\title{
Proteinuria and nephrotic syndrome, how to treat it
}

\begin{abstract}
Summary
Idiopathic nephrotic syndrome is the most frequent glomerulopathy in childhood. It affects $1-3 / 100$ thousand children under 16 years, more frequent between 2 and 10 years. Unknown cause and histology corresponds to disease due to minimal changes in more than $90 \%$ of cases or focal and segmental glomerulosclerosis.

The aim of the treatment is to induce and maintain remission of the disease, decreasing the risks secondary to proteinuria and minimizing the adverse effects of the treatments, especially due to the prolonged use of corticosteroids. 80 to $90 \%$ respond to steroids (corticosensitive nephrotic syndrome), with good long-term prognosis with preservation of renal function over time. $70 \%$ of patients with corticosensitive nephrotic syndrome have one or more relapses in their evolution, and of these, half with frequent relapses or corticodependent, a group that concentrates the risk of steroid toxicity. Patients with steroid-resistant nephrotic syndrome have a poor prognosis, evolving $50 \%$ to terminal chronic renal failure.
\end{abstract}

Volume 8 Issue 6 - 2018

\author{
Júlia Morata Alba', Laia Morata Alba² \\ 'Medical Specialist in Pediatrics, Lluís Alcanyís Hospital, Spain \\ ${ }^{2}$ Medical specialist in family and community medicine, Lluís
} Alcanyís Hospital, Spain

Correspondence: Júlia Morata Alba, Medical Specialist in Pediatrics, Pediatrics Service, Pediatric Nephrology, Lluís Alcanyís Hospital, Xàtiva, Valencia, Spain, Postal address: Carretera XàtivaSilla, km 2, 46800 Xàtiva (Valencia), Tel 677844000,

Email juliamarataalba@gmail.com

Received: October 18,2018 | Published: November 23, 2018

Keywords: proteinuria, corticoids, edema, kidney

\section{Introduction}

The definition of Nephrotic Syndromme (NS): protein/Creatinine in isolated urination $>2 \mathrm{mg} / \mathrm{mg}$ or in 24-hour urine $>40 \mathrm{mg} / \mathrm{m}^{2} /$ hour, hypoalbuminemia $(<2.5 \mathrm{~g} / \mathrm{dl})$, dyslipemia and generalized edema.

Idiopathic nephrotic syndrome (INS) is a podocytopathy of unknown etiology with immunological/structural podocyte lesion of the glomerular filtration diaphragm.

It is characterized by nephrotic range proteinuria, hypoalbuminemia and generalized edema. ${ }^{1,2}$

In Table I, the definitions. ${ }^{2,3}$

\section{Epidemiology and etiology}

$90 \%$ of Nephrotic Syndromes are idiopathic or primary.

The majority begin between 2 and 10 years, corresponding to idiopathic Nephrotic Syndrome (INS) or primary NS in $90 \% .^{2}$ The incidence in paediatric population less than 16 years old is $2-7$ new cases per 100,000 children per year, with a prevalence of 15 cases per 100,000 children. It occurs preferably between 2 and 8 years of age, with maximum incidence between 3-5 years. In children it is twice as frequent in males, a difference that does not exist in adolescents and adults.

Those initiated in children less than one year old usually have a genetic cause. ${ }^{4}$

INS responds $80-90 \%$ to corticosteroid treatment. The most frequent histopathology is minimal changes. The second in frequency, focal and segmental glomerulosclerosis, with a response rate to corticosteroids of $20-50 \%{ }^{2}$

There are other causes, less frequent in paediatrics, of secondary NS to systemic lupus erythematosus, glomerulonephritis, Schöenlein Henoch purpura, vasculitis, malignancies and infections.

\section{Evolution}

Idiopathic nephrotic syndrome (INS) responds in $80-90 \%$ of cases to corticosteroid treatment. $80-90 \%$ present one or more relapses, but maintain adequate response to corticoids, with good long-term prognosis and normal renal function. Patients resistant to steroids (mostly focal and segmental glomerulonephritis) have poor long-term prognosis and 50\% develop chronic renal disease and $10-30 \%$ present genetic mutations for structural proteins of the podocyte. ${ }^{5}$

The objective of INS treatment is to achieve remission and minimize the secondary risks of proteinuria (dyslipidemia, invasive bacterial infections, thromboembolic phenomena and malnutrition) and corticosteroids (linear growth stoppage, behavioral changes, obesity, Cushing syndrome, high blood pressure, cataracts, glucose intolerance and bone demineralization). ${ }^{3}$

Follow-up requires periodic monitoring of development and growth, symptomatic treatment, correct dosage of treatment and prevention of side effects.

\section{Treatment}

Treatment of the first episode of idiopathic nephrotic syndrome is single dose oral prednisone $\left(60 \mathrm{mg} / \mathrm{m}^{2} /\right.$ day or $2 \mathrm{mg} / \mathrm{kg} /$ day $)$ in the morning.

Treatment of the first episode of idiopathic nephrotic syndrome is prednisone in a single morning dose orally.

a. Daily: $60 \mathrm{mg} / \mathrm{m}^{2}$ or $2 \mathrm{mg} / \mathrm{kg}$ daily, maximum $60 \mathrm{mg}$, for $4-6$ weeks.

b. Subsequently: $40 \mathrm{mg} / \mathrm{m}^{2}$ or $1.5 \mathrm{mg} / \mathrm{kg}$ on alternate days, maximum $40 \mathrm{mg}$, for 4-6 weeks. Then decrease the dose progressively in 1 to 3 months until it is suspended.

The optimal dose and duration of treatment of the first episode are controversial. Prospective studies and meta-analysis have shown 
that prednisone treatments of 3 to 6 months in the first episode allow sustained remissions and decrease the frequency of relapses, ${ }^{6}$ two recent randomized clinical studies of good methodological quality showed that prolongation of steroid treatment from 3 to 6 months did not decrease the frequency of relapses at 12 months follow-up, nor the proportion of patients with frequent relapses and need for other immunosuppressive treatments, despite a higher cumulative dose. ${ }^{7,8}$

Treatment of relapses is with prednisone but according to the following protocol:

Prednisone $60 \mathrm{mg} / \mathrm{m}^{2}$ or $2 \mathrm{mg} / \mathrm{kg}$ (maximum $60 \mathrm{mg}$ ) in a daily dose until complete remission for at least 3 days, then $40 \mathrm{mg} / \mathrm{m}^{2}$ or 1.5 $\mathrm{mg} / \mathrm{kg}$ (maximum $40 \mathrm{mg}$ ) every other day for 4 weeks.

$40-45 \%$ of corticosensitive cases have frequent relapses or corticodependence. ${ }^{3}$ Factors associated with greater risk are: shorter time of first relapse (more consistent marker), number of relapses in the first 6 months, younger age and hematuria at onset, male sex and longer time in first remission. ${ }^{2,3}$

The long-term prognosis of renal function for most cases is good.

In children with corticodependent nephrotic syndrome the choice of treatment should assess the benefits with adverse effects. In summary we will list the treatment options in these cases:

1. Prednisone: prolong the therapy for a period of 6 to 18 months, at the lowest possible dose, to maintain remission without undesirable adverse effects. ${ }^{3,9}$

In order to reduce the risk of relapse in patients receiving prednisone on alternate days, in case of respiratory or other infections, it is suggested to administer the dose of prednisone daily for 7 days.

2. Steroid-sparing agents: indicated when there are adverse effects of corticosteroids or relapses with prednisone $>10 \mathrm{mg} / \mathrm{m}^{2}$ or $0.5 \mathrm{mg} /$ $\mathrm{kg}$ on alternate days (or equivalent in daily dose). A meta-analysis of 32 studies showed that alkylating agents and cyclosporine reduced the number of relapses in nephrotic syndrome with frequent relapses when compared with prednisone alone.,

Considering the cost-benefit ratio, the following order is suggested: cyclophosphamide, calcineurin inhibitors (Cyclosporine, Tacrolimus), mycophenolate mofetil, Rituximab.

Finally, it should be noted that renal biopsy (for optical microscopy, immunofluorescence and electron microscopy $)^{2}$ in cases of nephrotic syndrome will only be necessary in patients who do not respond to corticoids or who show histological characteristics different from disease due to minimal changes such as these:

I. Age less than one year old.

II. Corticorresistant NS.

III. NS associated with macroscopic hematuria, hypertension, renal failure (VFG $<90 \mathrm{ml} / \mathrm{min} / 1.73 \mathrm{~m}^{2}$ ), hypocomplementemia.

IV. Decreased renal function in children receiving therapy with calcineurin inhibitors.

In the case presented, renal biopsy was not performed due to the suspicion of minimal NS changes, both due to clinical evolution and family history.

\section{Clinical case}

We present a clinical case of corticodependent nephrotic syndrome with marked family history, taking advantage to review this not infrequent entity.

23-month-old boy with generalized edema. They referred swollen eyelids and progressively edematous appearance up to lower limbs. Decrease in diuresis, of macroscopically normal appearance, without another clinic. No history of stings or traumatisms. Respiratory infection two weeks before.

No personal history of interest. Family history: Father and paternal aunt corticodependent nephrotic syndrome, minimal changes (father from 14 to 25 years). Sister of 6 years old and healthy mother.

Exploration: Apyretic. Weight in p85, Size in p15, body surface $0.55 \mathrm{~m}^{2}$, PA 86/52 mmHg, FC 120 lpm, FR $32 \mathrm{rpm}$. Good overall appearance. Complete normal examination except discreetly globular abdomen with slight umbilical protrusion and bilateral palpebral edema, in pretibial region and dorsum of feet, without pitting.

On suspicion of proteinuria (nephrotic range) urine sediment was requested: $\mathrm{pH} 6.5$, density 1020 , proteinuria of $500 \mathrm{mg} / \mathrm{dL}$, red blood cells 10/uL. Protein/creatinine ratio (Prot/Cr) in isolated miction of $11 \mathrm{mg} / \mathrm{mg}$.

Blood analysis (hemogram, chemistry, venous gasometry) was normal except hypoalbuminemia $(2.0 \mathrm{~g} / \mathrm{dL})$, hypercholesterolemia (total cholesterol of $444 \mathrm{mg} / \mathrm{dL}$, triglycerides $182 \mathrm{mg} / \mathrm{dL}$, HDLCholesterol $68.5 \mathrm{mg} / \mathrm{dL}$, LDL-Cholesterol $339.1 \mathrm{mg} / \mathrm{dL}$ ). Serology, coagulation and detection of streptococcus in pharynx were negative. Renal ultrasound was normal.

Nephrotic syndrome was confirmed and after tuberculin test (negative), oral corticoid treatment was initiated according to protocol at $60 \mathrm{mg} / \mathrm{m}^{2} /$ day. Omeprazole and vitamin D and calcium supplements were associated.

Daily intake and diuresis were controlled, with negative balances and progressive disappearance of edemas and weight loss without signs of complication. At all times normotension and stable constants.

After 8 days of admission, proteinuria was negative, being the day of high isolated miction the protein $/ \mathrm{Cr}$ ratio $0.77 \mathrm{mg} / \mathrm{mg}$.

It was controlled in consultations of Pediatric Nephrology being able to carry out pattern of withdrawal of corticoids according to protocol, but to 15 days of the complete withdrawal and coinciding with afebrile respiratory infections process the proteinuria reappeared restarting pattern of corticoids to $60 \mathrm{mg} / \mathrm{m}^{2} /$ day.

Initially there was good response to corticoids with disappearance of proteinuria at 5-6 days but in the phase of withdrawal the proteinuria reappeared and this was repeated in three more occasions. Given the evolution and before suspicion of corticodependent nephrotic syndrome, treatment with cyclophosphamide was initiated with progressive withdrawal of the corticoid with good initial response, but in less than 2 months of having finished the treatment the proteinuria reappeared in nephrotic range being treated with corticoid pattern and before signs of corticodependence with several relapses it was decided to initiate treatment with mycophenolate mofetil that was maintained during a year, without objectifying proteinuria until the present moment. 


\section{Discussion}

Nephrotic syndrome is defined by proteinuria in the nephrotic range (protein/Creatinine in isolated urination $>2 \mathrm{mg} / \mathrm{mg}$ or in 24-hour urine $>40 \mathrm{mg} / \mathrm{m}^{2} /$ hour $)$, hypoalbuminemia $(<2.5 \mathrm{~g} / \mathrm{dl})$, dyslipemia and generalized edema ${ }^{1,2}$ as our case. The age of the patient described is among the most frequent (2 to 10 years) for INS or primary SN. ${ }^{2}$ It was one of the $10-20 \%$, according to the bibliography, ${ }^{2,3}$ that does not respond correctly to corticosteroid treatment.

Our patient (Table I) was a corticodependent nephrotic syndrome that evolved favourably but required several steroid-sparing agents such as cyclophosphamide (not good response) and mycophenolate mofetil.

Table I Classification Nephrotic syndrome

\begin{tabular}{|c|c|}
\hline Classification & Definition \\
\hline Nephrotic syndrome & $\begin{array}{l}\text { Edema, hypoalbuminemia }<2.5 \mathrm{mg} / \mathrm{dl} \text { and proteinuria in nephrotic range (Proteinuria/Creatinine (isolated } \\
\text { urination): }>2 \mathrm{mg} / \mathrm{mg} \text { or in } 24 \text {-hour urine }>40 \mathrm{mg} / \mathrm{m}^{2} / \text { hour) }\end{array}$ \\
\hline Complete referral & Prot $/ \mathrm{Cr}<0.2$ or $<1+$ urine test strip, for three consecutive days. Resolution of edema and albumin $\geq 3.5 \mathrm{mg} / \mathrm{dl}$ \\
\hline Partial remission & Prot/Cr between $0.2-2$, and albuminemia $>3 \mathrm{mg} / \mathrm{dl}$ \\
\hline Corticorresistance & Failure to achieve complete remission after 8 weeks of corticosteroid treatment \\
\hline Relapse & Prot $/ \mathrm{Cr}>2$ or $>3+$ urine test strip for 3 consecutive days \\
\hline Infrequent relapser & A relapse within 6 months of initial response or one to 3 relapses within 12 months \\
\hline Frequent relapser & 2 or more relapses in 6 months of initial response, or 4 or more relapses in 12 months \\
\hline Corticodependence & 2 consecutive relapses during corticosteroid treatment, or within 14 days of withdrawal \\
\hline Secondary corticorre & Persistent proteinuria for 4 or more weeks of corticosteroids after one or more remissions \\
\hline
\end{tabular}

Cases that start in less than one year are usually of genetic cause. ${ }^{5}$ Our patient was 23 months old but pointed out that there was an important family burden (father and paternal aunt) with corticodependent nephrotic syndrome, confirmed in both cases with renal biopsy as minimum changes (most frequent histopathology) and in both cases with good evolution of renal function so that no genetic study or renal biopsy was performed in the patient presented.

\section{Conclusion}

To know how to diagnose a nephrotic syndrome and how to treat it (with the peculiarities of the treatment according to the clinical evolution) as well as the follow-up to be carried out. These patients will be controlled by Pediatric Nephrologists but every Pediatrician (Primary or Specialized Care) must know their diagnosis and management, as early diagnosis is important.

\section{References}

1. Hodson E. The management of idiopathic nephrotic syndrome in children. Paediatr Drugs. 2003;5:335-349.

2. Hevia P, Nazal V, Rosati MP, Quiroz L, Alarcón C, et al. Síndrome nefrótico idiopático: recomendaciones de la Rama de Nefrología de la Sociedad Chilena de Pediatría. Rev Chil Pediatr. 2015;86(4):291-298.
3. KDIGO Clinical Practice Guideline for Glomerulonephritis. Kidney Int Suppl. 2012;2:139-274.

4. Jalanko H. Congenital nephrotic syndrome. Pediatr Nephrol. 2009; 24:2121-2128.

5. Azócar M. El síndrome nefrótico y el diagnóstico genético en Pediatría. Rev Chil Pediatr. 2011;82:12-20.

6. Teeninga N, Kist-van Holthe JE, van Rijswijk N, de Mos NI, et al. Extending prednisolone treatment does not reduce relapses in childhood nephrotic syndrome. J Am Soc Nephrol. 2013;24:149-159.

7. Sinha A, Saha A, Kumar M, Sharma S, Afzal K, et al. Extending initial prednisolone treatment in a randomized control trial from 3 to 6 months did not significantly influence the course of illness in children with steroid-sensitive nephrotic syndrome. Kidney Int. 2014;87:1-8.

8. Yoshikawa N, Nakanishi K, Sako M, Oba MS, Mori R, et al. A multicenter randomized trial indicates initial prednisolone treatment for childhood nephrotic syndrome for two months is not inferior to sixmonth treatment. Kidney Int. 2014;87:225-232.

9. Bagga A, Ali U, Banerjee S. Management of steroid sensitive nephrotic syndrome: revised guidelines. Indian Pediatr. 2008;45:203-214.

10. Pravitsitthikul N, Willis NS, Hodson EM, Craig JC. Non-corticosteroid immunosuppressive medications for steroid-sensitive nephrotic syndrome in children. Cochrane Database Syst Rev. 2013;10:CD002290. 